\title{
The Epidemiology, Evolution, and Treatment of KPC-Producing Organisms
}

\author{
Ann Marie Porreca ${ }^{1} \cdot$ Kaede V. Sullivan ${ }^{2} \cdot$ Jason C. Gallagher $^{1}$ \\ Published online: 5 May 2018 \\ (C) Springer Science+Business Media, LLC, part of Springer Nature 2018
}

\begin{abstract}
Purpose of Review The purpose of this review is to investigate the evolution and epidemiology of Klebsiella pneumoniae carbapenemase (KPC)-producing organisms and the current and future treatment options for infections caused by KPCproducing isolates.

Recent Findings The emergence of resistance in Enterobacteriaceae producing carbapenemases globally has increased the challenges in treating infections caused by these organisms. One of the prominent mechanisms of resistance is the production of KPC enzymes. Infections caused by organisms producing KPCs have limited treatment options and are associated with poor clinical outcomes. The rapid rise of KPC-producing organisms necessitated the use of drugs with pharmacokinetic and toxicity limitations, including polymyxins, tigecycline, fosfomycin, and aminoglycosides. The availability of new beta-lactamase inhibitor combinations that are effective against KPC-producing organisms represent an advance in safety and efficacy. Several agents are currently being studied that have activity against KPC-producing organisms and appear to represent promising additions to our armamentarium.

Summary KPC-producing organisms cause infections with high morbidity and mortality. Limited treatment options are available, though new therapies have been developed. Pipeline agents are likely to have a place in therapy for the treatment of infections caused by KPC-producing isolates.
\end{abstract}

Keywords Carbapenemases $\cdot \mathrm{KPC} \cdot$ Multi-drug resistance $\cdot \mathrm{KPC}$ treatment $\cdot \mathrm{KPC}$ infections $\cdot \mathrm{KPC}$ epidemiology

\section{Introduction}

The emergence of resistant Enterobacteriaceae that produce carbapenemases globally has led to the development of serious infections associated with significant morbidity and mortality $[1 \bullet \cdot, 2]$. In 2014, the World Health Organization (WHO) released a report that stated that carbapenem-resistant Klebsiella pneumoniae has spread to all regions of the world [3••]. The CDC currently reports that all states in the United States, with the exception of Maine and Idaho, have reported

This article is part of the Topical Collection on Antimicrobial Development and Drug Resistance

Jason C. Gallagher

Jason.gallagher@temple.edu

1 Temple University School of Pharmacy, 3307 North Broad Street, Philadelphia, PA, USA

2 Lewis Katz School of Medicine at Temple University, Philadelphia, PA, USA cases of KPC-producing organisms [4•]. There are multiple elements that contributed to the rapid spread of KPCs, such as plasmid borne genes and widespread international travel [5•].

Infections caused by these organisms are often difficult to treat due to resistance. Agents that are used include carbapenem combinations, polymyxins, fosfomycin, tigecycline, aminoglycosides, ceftazidime-avibactam, and meropenemvaborbactam, however, trials supporting their use are uncommon. New treatments with activity against KPCs are currently being studied to help mitigate the threat of resistance.

This paper will review the evolution and epidemiology of KPCs, current treatment options, and pipeline antibiotics for infections caused by KPC-producing organisms.

\section{Evolution and Epidemology}

KPC enzymes are class A carbapenemases that contain a serine residue in the active site and are comprised of 265-269 amino acids. The term "KPC" arose from "Klebsiella 
pneumoniae carbapenemase," as they were first identified in this organism [6]. To date, at least nineteen variants of KPC have been reported although KPC-2 and KPC-3 appear to be most prevalent [7].

KPC-producing organisms typically exhibit high levels of penicillin and cephalosporin resistance and variable carbapenem resistance. However, unlike other Ambler Class A betalactamase producers, KPCs are insufficiently inhibited by the beta-lactam-based beta-lactamase inhibitors clavulanate, tazobactam, and sulbactam [8]. KPC-producing organisms also tend to be multi-drug resistant as $b l a_{K P C}$ is carried on large plasmids with accompanying resistance determinants, including those responsible for resistance to aminoglycosides, quinolones, trimethoprim, sulfonamides, and tetracyclines $[9,10]$.

The first organism harboring $b l a_{K P C}$ was a $K$. pneumoniae isolate recovered in 1996 from a patient in North Carolina [11]. In 1998, bla $_{K P C}$ was identified in an isolate of Salmonella cubana that was recovered from the stool of a 4-year-old child with gastroenteritis in Maryland [12]. In the same year, KPC was detected in K. pneumoniae isolated from four adult patients in a Baltimore hospital and $K$. oxytoca in a patient from New York $[12,13]$. In 2000-2001, a New York City hospital reported the first known outbreak of hospital-acquired KPC-producing organisms, which involved 14 infected patients, eight of whom died as a result of their infection [14]. By the mid-2000s, some hospitals in New York City were reporting that nearly half of their $K$. pneumoniae isolates carried $b a_{K P C}$ genes [15•]. The CDC currently reports that all states in the United States with the exception of Maine and Idaho have reported infections with bacteria containing $b l a_{K P C}[4 \cdot]$. Interestingly, epidemiologists in New York City recently reported significant declines in prevalence of KPC-producers and suggested that reduction of indwelling device utilization (e.g., urinary catheters), improved techniques for sterilization of endoscopes, and application of infection prevention strategies may have contributed to this decline [16•]. Additional surveillance data will be required to determine if this trend occurs in other parts of the USA and to see if it continues.

The first report of a KPC-producing organism outside of the United States was a patient with prostatic carcinoma who had a bilateral nephrostomy performed in December 2004 at a New York City hospital. He was admitted to a hospital in Paris in February 2005 for acute urine retention. K. pneumoniae with $b l a_{K P C}$ was isolated from urine and blood cultures [17]. Additional early cases were reported in Brazil, the United Kingdom, France, and China. Subsequently, KPCs have disseminated rapidly throughout the globe and have been detected in virtually all clinically relevant Enterobacteriaceae [18].

A number of factors contributed to the rapid spread of KPC enzymes. First, $b l a_{K P C}$ is plasmid-borne. Plasmids with $b l a_{K P C}$ undergo horizontal transfer through conjugation with other bacterial cells. Thus, rapid movement of $b l a_{K P C}$ from cell-to-cell is a major contributor to its general spread and accompanying resistance determinants. Second, by the late 2000s, multilocus sequencing typing (MLST) revealed that while $b l a_{K P C}$ is present in over 100 different strains of $K$ pneumoniae, ST258 predominates in the United States and around the world. The reason underlying the success of ST258 is unclear but its remarkable ability to disseminate suggests a possible selective or fitness advantage over other clones [5•]. Finally, widespread international travel most certainly facilitated intercontinental transmission of organisms harboring $b l a_{K P C}$.

Outbreaks involving KPC-producing organisms have been described primarily in healthcare settings [19••]. Risk factors for acquisition of KPC-producing organisms are not specific, but include exposure to acute care hospitals or long-term acute care facilities, higher degrees of comorbidity, prior antibiotic use, elevated colonization pressure in endemic settings, and the prolonged use of indwelling and central venous catheters $[14,19 \bullet, 20 \bullet, 21]$. Transfer of patients between long-term acute care hospitals (LTACs) with high KPC levels and other healthcare facilities has been identified as an important mechanism of hospital-to-hospital transmission [22]. Lübbert et al. showed that following an outbreak involving KPC-producing organisms, nearly two-thirds of the 84 colonized study patients spontaneously cleared and tested negative repeatedly by KPC PCR after 6 months, but that colonization for $>3$ years was observed in some patients. This underscored the importance of following the colonization status of these cases and consistently applying isolation precautions when they access healthcare [23]. Finally, environmental contamination is thought to be an important mechanism of transmission of KPC-producing organisms. Leitner et al. described a prolonged outbreak involving $K$. oxytoca with bla $_{K P C}$ in an Austrian hematology ward. Identical ST4 clones of $b l a_{K P C-2}$ were recovered from the sinks in the rooms where cases were admitted in addition to the sink of a medication room. The authors hypothesized that water hitting the mesh in the sink drains aerosolized organisms with KPC when patients were using the sinks for personal hygiene. Renewed enforcement of contact precautions, hand hygiene, and cleaning of the environment (including sinks and equipment) eventually controlled the outbreak [24•].

The use of bundled interventions that include $2 \%$ chlorhexidine baths, contact precautions, enhanced environmental cleaning, surveillance cultures, serial point prevalence surveillance, and personnel training has been reported to mitigate patient-to-patient transmission [24•, 25, 26•]. The use of fecal microbiota transplantation (FMT) to displace colonizing multi-drug resistant organisms is a new and novel approach that is under investigation $[27 \bullet \bullet]$.

\section{Treatment}

Treatment options for infections caused by KPC-producing organisms are limited and outcomes for these infections are 
generally poor. It has been found that patients with bloodstream infections caused by carbapenem-resistant organisms are more likely to have a longer hospital stay, be admitted to an intensive care unit, and suffer increased mortality compared to patients with either ESBL-producing $K$. pneumoniae or susceptible $K$. pneumoniae $[1 \bullet \bullet, 28]$. Delays in administration of active therapy to patients with KPC-producing infections are common and may affect outcomes, including mortality [29-31]. Appropriate treatment is a modifiable predictor of infection outcome.

Current antimicrobial options for infections caused by KPC-producing organisms are limited by their pharmacokinetics, toxicities, and lack of strong clinical evidence supporting their efficacy. Two new beta-lactamase inhibitor combinations have been made available with in the last few years that have been shown to be safer and possibly more efficacious for the treatment of infections caused by KPCproducing organisms compared to some of the older agents, however, supportive data is limited. In addition, KPCs continue to evolve and have developed resistance against some of the current treatment options. Below are currently available treatment options and evidence supporting (or not supporting) their use.

\section{Carbapenem Combinations}

Carbapenems are counterintuitive choices of therapy for KPCproducing organisms, but they have been described as useful in some studies, particularly when administered as prolonged or continuous infusions or in combination with other agents, particularly for organisms with only moderately elevated minimum inhibitory concentrations (MICs). However, KPCproducing $K$. pneumoniae exhibit a marked inoculum effect and MICs may not predict the efficacy of carbapenems against KPC-producing infections [32]. Combination of a prolonged carbapenem infusion with another agent with activity against carbapenemases is a better option than carbapenems alone. A multi-centered, retrospective, cohort study with 661 adult patients illustrated that combination regimens that included meropenem were associated with significantly higher survival rates when the KPC-producing isolate had a meropenem MIC $\leq 8 \mu \mathrm{g} / \mathrm{mL}$ [33].

Dual carbapenem therapy has also been studied for the treatment of infections caused by KPC-producing organisms. This combination is active due to the higher affinity of KPCs for ertapenem, allowing it to function as a suicide substrate and enhance the activity of the concomitant carbapenem [34]. A few case reports and series support the use of dual carbapenem therapy for treatment of infections caused by KPC-producing organisms $[35 \cdot, 36]$. A recent case-control study investigated the clinical impact of regimens including two carbapenems in 144 patients with infections caused by carbapenem-resistant
K. pneumoniae (90\% producing KPCs) and found that 28-day mortality was lower in patients who received a double-carbapenem regimen compared to those who received treatment with dual or triple agent combinations of colistin, tigecycline, and gentamicin $(p=0.04)$. Likewise, clinical cure and microbiological eradication were significantly higher when double-carbapenem therapy was used in patients infected with carbapenemresistant $K$. pneumoniae resistant to colistin $(13 / 20$ $(65 \%)$ versus $10 / 32(31.3 \%), p=0.03$ and $11 / 19(57.9 \%)$ versus $7 / 27(25.9 \%), p=0.04$, respectively) [37••].

Although the use of carbapenem-based combination regimens for the treatment of infections caused by KPCproducing organisms has some utility, evidence is limited and testing for synergy is difficult. There are pros and cons with using these regimens (Table 1). If one of them is used, it is important that the pharmacodynamics of the carbapenem used be maximized through prolonged or continuous infusions.

\section{Polymyxins}

The polymyxins are a class of polypeptide antibiotics that have been revitalized for the treatment of infections caused by resistant Gram-negative organisms, including those producing KPCs. Polymyxins have in vitro activity against most $K$. pneumoniae, however, heteroresistance is common [38••, $39,40]$. When the isolate is exposed to a polymyxin, killing of the susceptible population amplifies resistant subpopulations. In vitro studies suggest that polymyxin monotherapy may lead to emergence of resistance and that they should be administered in conjunction with other agents $[41,42 \bullet \cdot$. Carbapenems have been studied in combination with polymyxins and showed in vitro synergy with polymyxins against carbapenem-resistant $K$. pneumoniae, including KPCproducing $K$. pneumoniae $[42 \bullet \bullet, 43]$.

When using polymyxins, appropriate dosing and potential adverse effects are concerns. Modern pharmacokinetic and pharmacodynamic studies show that dosing recommendations in both polymyxin B and colistin package inserts are inaccurate $[44,45]$. The prodrug colistimethate sodium (CMS) is cleared renally while the active drug colistin is eliminated through non-renal means. However, since colistin is administered as CMS, the amount of formed active drug is dependent on renal function. In fact, these studies show difficulty in achieving adequate plasma concentrations of formed colistin in patients with a creatinine clearance $>80 \mathrm{~mL} / \mathrm{min} / 1.73 \mathrm{~m}^{2}$ [46••]. The ability to reach therapeutically useful lung concentrations is also uncertain [47••]. In contrast, pharmacokinetic studies investigating polymyxin B showed that doses should not be based on renal function as recommended in the package insert because polymyxin B is not renally cleared [48]. Accordingly, colistin would be the better choice of the 
Table 1 Pros and cons of treatments for infections caused by Klebsiella pneumoniae carbapenemase-producing organisms

\begin{tabular}{|c|c|c|}
\hline Treatment options & Pros & Cons \\
\hline Carbapenem combinations & - Less expensive compared to other options & $\begin{array}{l}\text { - Optimal combinations difficult to discern } \\
\text { - In vitro testing of combinations difficult to perform } \\
\text { - Limited clinical evidence supported by well-designed } \\
\text { studies for treatment of infections caused by } \\
\text { KPC-producing organisms }\end{array}$ \\
\hline Polymyxins & $\begin{array}{l}\cdot \text { High susceptibility rates } \\
\text { - Low cost }\end{array}$ & $\begin{array}{l}\text { - Colistin has unpredictable PK } \\
\text { - High risk of nephrotoxicity (higher in colistin) } \\
\text { - Polymyxin B is unavailable in many areas } \\
\text { - Higher mortality rates seen in patients receiving } \\
\text { colistin-containing regimens compared to } \\
\text { beta-lactam inhibitor regimens } \\
\text { - Selection of resistance to class when used as monotherapy }\end{array}$ \\
\hline Fosfomycin & $\begin{array}{l}\text { - Available orally } \\
\text { - Generally safe option } \\
\text { - Additive with other agents }\end{array}$ & $\begin{array}{l}\text { - Resistance can develop when used as monotherapy } \\
\text { - IV formulation only available in Europe } \\
\text { - Oral formulation only effective for cystitis } \\
\text { - Limited clinical evidence supporting the use of oral } \\
\text { fosfomycin for treatment of infections caused } \\
\text { by KPC producing organisms } \\
\text { - Cost }\end{array}$ \\
\hline Aminoglycosides & $\begin{array}{l}\text { - Can be used as monotherapy for } \\
\text { treatment of UTIs } \\
\text { - Shown to have clinical benefit when } \\
\text { used in combination with another agent }\end{array}$ & $\begin{array}{l}\text { - Nephrotoxicity and ototoxicity } \\
\text { - High mortality rates when used as monotherapy } \\
\text { for infections (not UTIs) } \\
\text { - May need high doses for high MICs }\end{array}$ \\
\hline Tigecycline & $\begin{array}{l}\text { - High susceptibility rates } \\
\text { - Mortality benefit seen when given in combinations }\end{array}$ & $\begin{array}{l}\text { - Boxed warning for higher all-cause mortality } \\
\text { - Low serum drug concentrations } \\
\text { - Higher doses may be needed for pneumonia } \\
\text { - GI toxicity } \\
\text { - Resistance can develop to drug during treatment }\end{array}$ \\
\hline Ceftazidime-avibactam & $\begin{array}{l}\text { - Mortality benefit seen when compared to colistin } \\
\text { - Contains novel non-beta-lactam-beta-lactamase inhibitor } \\
\text { - Beta-lactam-based regimen }\end{array}$ & $\begin{array}{l}\text { - Resistance to drug has developed during treatment } \\
\text { - Cost }\end{array}$ \\
\hline Meropenem-vaborbactam & $\begin{array}{l}\text { - Superior to best available therapy in a } \\
\text { prospective study of carbapenem-resistant infections } \\
\text { - Contains novel boron-containing serine-beta } \\
\text { lactamase inhibitor } \\
\text { - Beta-lactam-based regimen }\end{array}$ & - Cost \\
\hline
\end{tabular}

${ }^{1}$ KPC: Klebsiella pneumoniae carbapenemase

${ }^{2} \mathrm{PK}$ : Pharmacokinetics

${ }^{3}$ IV: Intravenous

${ }^{4}$ UTIs: Urinary tract infections

${ }^{5} \mathrm{MIC}$ : Minimum inhibitory concentrations

${ }^{6}$ GI: Gastrointestinal

polymyxins for urinary tract infections (UTIs). Although both agents have the potential to cause nephrotoxicity and neurotoxicity, several comparisons have shown a significantly higher risk of acute kidney injury in patients who received colistin compared to polymyxin B $[49 \cdot \bullet, 50,51]$.
In practice, these agents are limited by their toxicity, the unfavorable pharmacokinetics of colistin, and a lack of availability of polymyxin B in some parts of the world. Though polymyxin-based regimens have been commonly used for KPC-producing infections, recent small studies of new beta- 
lactamase inhibitor combinations have shown favorable results compared to these polymyxin-containing regimens.

\section{Fosfomycin}

Fosfomycin is frequently active against KPC-producing organisms [52]. However, resistance develops rapidly when fosfomycin is used as monotherapy, therefore, combination therapies are recommended [53]. In vitro studies have evaluated fosfomycin in combination with imipenem, ertapenem, tigecycline, colistin, meropenem, gentamicin, and amikacin and showed additive effects against KPC-producing strains with fosfomycin and amikacin showing the most potent activity even when the causative bacteria were resistant to amikacin $[54,55 \bullet, 56]$.

The utility of fosfomycin is limited in the United States since it is only available as an oral formulation. Due to its moderate absorption, fosfomycin is limited to the treatment of urinary tract infections. While this is a limitation, UTIs are commonly caused by KPC-producing organisms. Only two case reports showing that it has been clinically effective against infections caused by KPC-producing organisms have been published [57]. A study of IV fosfomycin for UTIs for approval in the United States is currently being conducted (NCT02753946) so it may be a treatment option in combination with another agent in the future in the United States.

\section{Aminoglycosides}

Aminoglycosides are well-established agents that have potent bactericidal activity against Gram-negative bacteria [55•]. It is important to note that aminoglycosides do not have equal utility against KPC-producing isolates. When tested in vitro against $25 \mathrm{KPC}$-producing isolates, susceptibility rates were $48 \%$ to amikacin (CLSI breakpoint $\leq 16 \mathrm{mg} / \mathrm{mL}, 44 \%$ to gentamicin (at $\leq 4 \mathrm{mg} / \mathrm{mL}$ ) and $8 \%$ to tobramycin (at $\leq 4 \mathrm{mg} / \mathrm{mL}$ ) [56]. Notably, CLSI breakpoints are higher than those suggested by some other organizations, and if lower breakpoints are used many less isolates would be considered susceptible [58].

Based on limited data available, aminoglycosides appear to be a suitable option for the treatment of UTIs caused by KPCproducing isolates $[55 \bullet, 59,60 \bullet$. Patients in one small study of UTIs caused by carbapenem-resistant $K$. pneumoniae had significantly higher clearance rates when treated with an aminoglycoside ( $88 \%$ ) compared to those receiving either a polymyxin $(64 \%)$ or tigecycline $(43 \%)$ [61]. For other infections, evidence supporting aminoglycosides as monotherapy is lacking, and studies have shown a mortality rate from $6.3-80 \%$ in patients that received them alone [62]. This may be due to their limiting pharmacokinetic profile, however, they may have a place in therapy when given in combination with another antibiotic. A systematic review of 20 clinical studies evaluating patients being treated for infections caused by carbapenemase-producing $K$. pnemuoniae including KPCtype enzymes showed that the combination of aminoglycosides with a carbapenem had the lowest mortality rates [62].

The role in therapy for aminoglycosides as monotherapy should be limited to UTIs. They also have a role in combination regimens with other active agents, though the need for this may be somewhat mitigated by the introduction of the new beta-lactamase inhibitor combinations. Though evidence is lacking, they may also have an adjunctive role in as aerosolized agents in patients with pneumonia caused by KPCproducing organisms [63]. The utility of aminoglycosides must always be weighed against their well-known toxicities.

\section{Tigecycline}

Tigecycline, a glycyclcycline tetracycline, has broad spectrum activity including against KPC-producing Enterobacteriaceae. Some in vitro studies show all KPC-producing isolates to be susceptible to tigecycline [64]. However, clinicians should be cautious when using tigecycline since it has limitations. Resistance development during therapy has been seen in the setting of carbapenem-resistant $K$. pneumoniae bacteruria [65]. Pharmacokinetic limitations include bloodstream concentrations that average below the CLSI Enterobacteriaceae breakpoint of $2 \mathrm{mcg} / \mathrm{mL}$ due to its extensive tissue penetration [66]. Also, since tigecycline is eliminated primarily through biliary excretion, minimal concentrations in the bladder lead to questionable utility for UTIs. Finally, a clinical study of tigecycline compared with imipenem for ventilatorassociated pneumonia was statistically inferior to imipenem, leading to the concern that higher-than-approved doses may be necessary. Several small studies have evaluated the use of tigecycline in KPC-producing infections, in combination with other agents and often in higher doses than recommended in the labeling (200 mg loading dose, than $100 \mathrm{mg}$ IV q12 hours) [67-70]. One multicenter retrospective cohort study in 661 patients found that triple-combination therapy with colistin, tigecycline, and meropenem was associated with lower mortality [OR: $0.11 ; 95 \% \mathrm{CI}: 0.02-.69] ; p=0.01$, in bloodstream infections caused by KPC-producing isolates compared to single-drug regimens of colistin, tigecycline, or gentamicin [33].

The results of evaluations of tigecycline-contained studies have been variable and difficult to interpret due to the multiple regimens used in the studies, but some have shown a mortality benefit when using combination regimens that include tigecycline. It is important to note that these studies were conducted prior to the availability of the newer beta-lactamaseinhibitor-containing regimens and comparisons between these regimens are limited. In addition, any discussion of tigecycline warrants mention of the boxed warning of a higher risk of death compared to other antibacterial drugs [70]. This 
warrants caution when considering tigecycline when other highly active agents are available but should not prevent its use when they are not.

\section{Ceftazidime-Avibactam}

Ceftazidime-avibactam is a newly approved agent combining an antipseudomonal cephalosporin and novel non-beta-lactam beta-lactamase inhibitor. Avibactam has a diazabicyclooctane structure that is not based on the beta-lactam ring and does not function as a suicide substrate like beta-lactam-based inhibitors. It is also stable against KPC enzymes [71]. One surveillance study showed ceftazidime-avibactam active against 97.5\% (117/120) of KPC-producing clinical isolates [72]. Prospective studies support the in vivo efficacy of ceftazidime-avibactam against ceftazidime-resistant isolates, with one study showing it to be superior to best available therapy (BAT), mostly carbapenems, in UTIs caused by these organisms [73•]. There are limited but growing clinical data illustrating ceftazidime-avibactam efficacy in treating infections in humans caused by KPC-producing pathogens [74-76].

Two small studies have shown clinical efficacy of monotherapy ceftazidime-avibactam in treating a variety of infections caused by CRE [77••, 78, 79]. Two studies have been performed comparing ceftazidime-avibactam-based regimens with other regimens for CRE infections, predominantly caused by KPC-producing pathogens. The first retrospectively evaluated carbapenem-resistant K. pneumoniae (97\% KPCproducing strains) bloodstream infections and found that ceftazidime-avibactam treatment in these patients was associated with significantly higher clinical success 11/13 (85\%) compared to those that received another treatment regimen which included a carbapenem plus aminoglycoside, (12/ $25(48 \%) ; p=0.04)$ or colistin $(12 / 30(40 \%) ; p=0.009)$ and other regimens $(15 / 41(37 \%) ; p=0.004)[80 \bullet \cdot$. The second study was a multicenter observational study comparing ceftazidime-avibactam $(n=38)$ to colistin $(n=99)$ for the treatment of multiple types of infections caused by KPCproducing CRE. Most of these infections were bloodstream $(n=63,46 \%)$ and respiratory $(n=30,22 \%)$, and most patients received an additional anti-CRE agent. From a multivariate analysis, among patients treated with ceftazidime-avibactam versus colistin, all cause in-hospital mortality 30 days after the start of treatment was 3/38 (8\%) versus 33/99 (33\%), respectively. After adjustment, the 30-day mortality after starting treatment was $9 \%$ vs. $32 \%(p=0.0012)$, for ceftazidimeavibactam versus colistin, respectively [81••].

Resistance to ceftazidime-avibactam has been reported to emerge during therapy. In a retrospective study in one medical center, emergent ceftazidime-avibactam resistance was detected in 3/10 (30\%) of microbiological failures with carbapenemresistant $K$. pneumoniae in patients that were treated with it.
Most mutations have occurred within the KPC $\Omega$-loop position, resulting in enhanced ceftazidime binding and restricted avibactam binding $[82 \bullet \bullet, 83]$. It is important that clinicians are aware of the possibility of emergent resistance leading to ceftazidime-avibactam treatment failure, retesting susceptibilities if KPC-producing organisms are persistent in cultures.

\section{Meropenem-Vaborbactam}

Meropenem-vaborbactam received FDA approval in August 2017. Vaborbactam is a novel boron-containing serine-beta lactamase inhibitor that works by creating a covalent bond between its boron moiety and the serine side chain of betalactamases, preventing them from destroying beta-lactams. When tested in vitro against 133 clinical KPC-producing Enterobacteriaceae strains, 131 (98.5\%) were inhibited by meropenem-vaborbactam [84•].

The clinical data supporting meropenem-vaborbactam for KPC-producing infections is limited to a single randomized trial (TANGO-2). It investigated the efficacy of meropenemvaborbactam compared with investigator-chosen BAT in patients with serious infections caused by confirmed or suspected carbapenem-resistant Enterobacteriaceae. Randomization in the trial was stopped early after the results of an interim analysis showed statistically significant differences in favor of meropenem-vaborbactam over BAT for clinical cure at the test of cure visit (meropenem-vaborbactam $57.1 \%(16 / 28)$ versus BAT $26.7 \%$ (4/15); 30.5\% [95\% CI: $1.5 \%-59.5 \%$ ], $p=0.04$. Mortality at 28 days in the pooled patient population with bacteremia, hospital-acquired bacterial pneumonia, or ventilator-associated bacterial pneumonia was $17.9 \%(5 / 28)$ for meropenem-vaborbactam versus $33.3 \%(5 / 15)$ for BAT [85•].

\section{Treatments in Late Stage Development}

After years of stagnation, governmental attention and incentives have encouraged the development of new antibiotics. Several drugs in late-stage clinical development are active against KPC-producing organisms.

Cefiderocol is a cephalosporin with a novel mechanism of action. Unlike other beta-lactams, it contains a catechol moiety that acts like a siderophore, taking advantage of active iron transport mechanisms in bacteria instead of relying solely on porin channels to penetrate organisms. Cefiderocol has been shown to have potent in vitro activity against CRE, including both KPC-producing Enterobacteriaceae and those producing metallo-beta-lactamases [86]. Cefiderocol is currently under clinical development and recently a registration study was completed in patients with complicated urinary tract infection (cUTI) (APEKS*-cUTI) (NCT02321800) (Table 2). Cefiderocol met the primary efficacy endpoint and was 
superior to imipenem-cilastatin with a weighted difference in primary outcome of $18.58 \%$ (95\% CI $8.23 \%-28.92 \%)$. Additional Phase 3 trials are being conducted (Table 2).

Plazomicin is an aminoglycoside with activity against KPC-producing isolates. Two phase 3 trials have been completed looking at plazomicin for treatment of cUTI (NCT01970371) and serious infections due to CRE (NCT02486627) (Table 2). For the treatment of complicated urinary tract infections including pyelonephritis, a statistically significant difference favoring plazomicin over meropenem was demonstrated at test of cure (TOC) visit in clinical cure and microbiological failure, $81.7 \%$ versus $70.1 \%$, respectively, $11.6 \%$ (95\% confidence interval (CI): $2.7-$ $20.3 \%$ ) driven primarily by a higher microbiological eradication rate at TOC in the plazomicin group. In addition, at the late follow-up visit, the composite cure rate was significantly higher in the plazomicin group compared with the meropenem group. For the treatment of serious carbapenem infections, when used as a part of a combination regimen (tigecycline or meropenem), plazomicin $(n=17)$ compared to colistin $(n=20)$, plazomicin was associated with reduced all-cause mortality at day $28,11.8 \%$ vs. $40 \% ; 28.2 \%$ (95\%CI: $0.7-$ $52.5 \%$ ). In addition to lower mortality rates, it was associated with a favorable safety profile compared with colistin,

Table 2 Treatment options in late stage development

\begin{tabular}{|c|c|c|c|}
\hline Drug & Class & Indication studied and/or being studied & Notes \\
\hline \multirow[t]{3}{*}{$\begin{array}{l}\text { Cefiderocol } \\
(\mathrm{S}-649266)\end{array}$} & \multirow[t]{3}{*}{ Siderophore cephalosporin } & - $\mathrm{cUTI}^{1}$ with or without pyelonephritis & $\begin{array}{l}\text { - Novel mechanism of action that relies } \\
\text { on active iron transport }\end{array}$ \\
\hline & & $\begin{array}{l}\text { - Severe infections caused by carbapenem-resistant } \\
\text { Gram-negative } \\
\text { pathogens }\left(\mathrm{HCAP}^{2}, \mathrm{BSI}^{3}, \mathrm{HAP}^{4}\right. \\
\left.\text { sepsis, or } \mathrm{VAP}^{5}\right)\end{array}$ & $\begin{array}{l}\text { - High stability against hydrolysis by ESBLs } \\
\text { and carbapenemase-producing organisms } \\
\text { (including New Delhi metallo - beta- } \\
\text { lactamase) }\end{array}$ \\
\hline & & $\begin{array}{l}\text { - Treatment of nosocomial pneumonia } \\
\text { caused by Gram-negative pathogens }\end{array}$ & $\begin{array}{l}\text { - Showed superiority for the treatment of } \\
\text { cUTIs and acute pyelonephritis compared to } \\
\text { imipenem-cilastin }\end{array}$ \\
\hline \multirow[t]{5}{*}{ Plazomicin } & \multirow[t]{5}{*}{ Aminoglycoside } & - cUTI including acute pyelonephritis & $\begin{array}{l}\text { - Dosing strategies include using drug } \\
\text { monitoring }\end{array}$ \\
\hline & & \multirow[t]{4}{*}{$\begin{array}{l}\text { - Infections related to CRE (BSI, HAP, VAP, cUTI } \\
\text { including acute pyelonephritis) }\end{array}$} & - Potential for once daily dosing \\
\hline & & & $\begin{array}{l}\text { - Activity against aminoglycoside modifying } \\
\text { enzymes }\end{array}$ \\
\hline & & & $\begin{array}{l}\text { - Proved to significantly reduce } 28 \text {-day all } \\
\text { cause mortality when compared to colistin for } \\
\text { treatment of CRE BSI infections }\end{array}$ \\
\hline & & & - Superior to meropenem for cUTIs \\
\hline \multirow[t]{3}{*}{ Eravacycline } & \multirow[t]{3}{*}{ Tetracycline } & $\cdot \mathrm{cIAI}^{8}$ & $\begin{array}{l}\text { - Largely unaffected by efflux pumps and } \\
\text { ribosomal protected proteins }\end{array}$ \\
\hline & & \multirow[t]{2}{*}{ - cUTI including acute pyelonephritis } & $\begin{array}{l}\text { - Shown to be non-inferior for the treatment } \\
\text { of cIAIs compared to ertapenem }\end{array}$ \\
\hline & & & $\begin{array}{l}\text { - Did not achieve the primary endpoint when } \\
\text { compared to levofloxacin for the treatment of } \\
\text { cUTI }\end{array}$ \\
\hline \multirow[t]{2}{*}{$\begin{array}{l}\text { Imipenem- } \\
\text { relebactam }\end{array}$} & \multirow[t]{2}{*}{$\begin{array}{l}\text { Carbapenem-beta-lactamase } \\
\text { inhibitor }\end{array}$} & $\begin{array}{l}\text { - Imipenem - resistant infections } \\
\left.\text { (HAP, VAP, } \text { cIAI }^{8}, \mathrm{cUTI}\right)\end{array}$ & $\begin{array}{l}\text { - Beta-lactamase inhibitor is a } \\
\text { diazabicyclooctane inhibitor }\end{array}$ \\
\hline & & - HAP and VAP & - Currently being studied in phase III studies \\
\hline
\end{tabular}

${ }^{1}$ cUTI: Complicated urinary tract infection

${ }^{2}$ HCAP: Healthcare associated pneumonia

${ }^{3}$ BSI: Blood stream infection

${ }^{4}$ HAP: Hospital-acquired pneumonia

${ }^{5}$ VAP: Ventilator-acquired pneumonia

${ }^{6}$ ESBLs: Extend-spectrum-beta-lactamases

${ }^{7}$ CRE: Carbapenem Resistant Enterobacteriaceae

${ }^{8}$ cIAI: Complicated-intra-abdominal infection 
including a lower incidence and magnitude of serum creatinine elevations [87].

Relebactam is a bicyclic diazabicyclooctane, non-betalactam beta-lactamase inhibitor of class A (ESBLs and $\mathrm{KPCs}$ ) and class $\mathrm{C}$ beta-lactamases that is similar in structure to avibactam. It is being studied in combination with imipenem-cilastatin. An amount of $4 \mu \mathrm{g} / \mathrm{ml}$ relebactam was required for imipenem-resistant $K$. pneumoniae isolates expressing KPC carbapenemases to become susceptible to imipenem and reduced MICs of imipenem against Enterobacter spp. isolates, including imipenem-resistant strains producing KPC enzymes $[88 \bullet, 89]$. The efficacy and safety of imipenem-cilastatin-relebactam has been studied compared to the combination of colistin and imipenemcilastatin in a phase III trial of imipenem-resistant infections (NCT02452047). Results are pending (Table 2).

Eravacycline is a flurocycline tetracycline with a similar mechanism of action to other tetracyclines. This drug is different from others in its class because its antibacterial activity is barely affected by active drug efflux systems and ribosomal protection proteins [90]. Eravacycline has potent in vitro activity against KPC-producing E. coli and $K$. pneumoniae, with MIC90s of $0.5 \mu \mathrm{g} / \mathrm{ml}$ and $2 \mu \mathrm{g} / \mathrm{ml}$, respectively [91, 92•]. Two clinical trials investigating the use of eravacycline for cIAI (NCT01844856) and cUTI (NCT01978938) have been completed. For the treatment of cIAI, the rates of clinical cure at the test-of-cure visit were eravacycline $86.8 \%$ (191/220) versus ertapenem $87.6 \%$ (198/226) for the microbiological intent-to-treat population. The difference in clinical cure rates between the groups was $-0.80 \%(95 \% \mathrm{CI},-7.1-5.5 \%)[93 \bullet \cdot]$. However, when compared to levofloxacin for the treatment of complicated UTIs, eravacycline did not achieve the primary endpoint.

\section{Conclusion}

KPC-producing organisms cause infections with high morbidity and mortality. Limited treatment options are available, though new therapies have been developed. It is likely that the reported poor outcomes in patients with KPC-producing infections are partially due to both delays to active therapy and the historical need to use antibiotics with suboptimal pharmacokinetics and tolerability. Increased use of rapid diagnostics can help to address therapy delays, while new agents are beginning to address the latter.

Emerging data suggests that new beta-lactamase inhibitor combinations are superior choices of therapy for most patients, though more supportive data is needed. It should be noted that studies showing better outcomes with combination therapies for KPC-producing infections were conducted prior to the availability of new beta-lactamase inhibitor combinations. Pipeline agents are likely to have a place in therapy for the treatment of infections caused by KPC-producing isolates. However, KPCs will continue to evolve, and new agents or regimens should continue to be studied to mitigate the neverending threat of antibiotic resistance.

\section{Compliance with Ethical Standards}

Conflict of Interest Ann Marie Porreca, Kaede V. Sullivan, and Jason C. Gallagher declare that they have no conflict of interest.

Human and Animal Rights and Informed Consent This article does not contain any studies with human or animal subjects performed by any of the authors.

\section{References}

Papers of particular interest, published recently, have been highlighted as:

- Of importance

•• Of major importance

1.• Ben-David D, Kordevani R, Keller N, Tai I, Marzel O, Gal-Mor Y, et al. Outcome of carbapenem resistant Klebsiella pneumoniae bloodstream infections. Clin Microbiol Infect. 2017;18(1):54-60. https://doi.org/10.1111/j.1469-0691.2011.03478.x. This article illustrated the impact that carbapenem-resistant $K$. pneumoniae had on mortality in patients with bloodstream infections.

2. Patel G, Huprikar S, Factor SH, Jenkins SG, Calfee DP. Outcomes of carbapenem-resistant Klebsiella pneumoniae infection and the impact of antimicrobial and adjunctive therapies. Infect Control Hosp Epidemiol. 2008;29(12):1099-106. https://doi.org/10.1086/ 592412.

3.• World Health Organization. Global Antimicrobial Resistance Surveillance System. Manual for Early Implementation. WHO. 2015:1-44. http://www.who.int/drugresistance/en/ $\% 5$ Cnwww.who.int/about/licensing/copyright form/en/ index.\%5Cnhttp://apps.who.int/iris/bitstream/10665/188783/1/ 9789241549400_eng.pdf?ua $=1$. This reference is important because it emphasized the current emergence of Klebsiella pneumoniae carbapenemases globally.

4. Centers for Disease Control and Prevention. Tracking CRE. CDC. 2017;2010:2009-10. https://doi.org/10.1086/668770. This report revealed that all states, with exception of Maine and Idaho, reported cases of Klebsiella pneumoniae carbapenemaseproducing organisms

5. Pitout JDD, Nordmann P, Poirel L. Carbapenemase-producing Klebsiella pneumoniae, a key pathogen set for global nosocomial dominance. Antimicrob Agents Chemother. 2015;59(10):5873-84. https://doi.org/10.1128/AAC.01019-15. This paperrevealed how ST258 predominates in the United States and around the world, suggesting a possible selective or fitness advantage over other clones

6. Yigit H, Queenan AM, Rasheed JK, Biddle JW, Domench-Sanchez A, Alberti S, et al. Carbapenem-resistant strain of Klebsiella oxytoca harboring carbapenem-hydrolyzing beta-lactamase KPC2. Antimicrob Agents Chemother. 2003;47(12):3881-9. https://doi. org/10.1128/AAC.47.12.3881.

7. Stoesser N, Sheppard AE, Peirano G, Anson LW, Pankhurst L, Sebra $\mathrm{R}$, et al. Genomic epidemiology of global Klebsiella pneumoniae 
carbapenemase (KPC)-producing Escherichia coli. Sci Rep. 2017;7(1): 1-11. https://doi.org/10.1038/s41598-017-06256-2.

8. Pasteran FG, Otaegui L, Guerriero L, Radice G, Maggiora R, Rapoport M, et al. Klebsiella pneumoniae carbapenemase-2, Buenos Aires. Argentina Emerg Infect Diseas. 2008;14(7):117880. https://doi.org/10.3201/eid1407.070826.

9. Deshpande LM, Rhomberg PR, Sader HS, Jones RN. Emergence of serine carbapenemases (KPC and SME) among clinical strains of Enterobacteriaceae isolated in the United States medical centers: report from the MYSTIC program (1999-2005). Diagn Microbiol Infect Dis. 2006;56(4):367-72. https://doi.org/10.1016/j. diagmicrobio.2006.07.004.

10. Endimiani A, Choudhary Y, Bonomo RA. In vitro activity of NXL104 in combination with beta-lactams against Klebsiella pneumoniae isolates producing KPC carbapenemases. Antimicrob Agents Chemother. 2009;53(8):3599-601. https://doi.org/10.1128/ AAC.00641-09.

11. Yigit H, Queenan AM, Anderson GJ, Domenech-Sanchez A, Biddle JW, Steward CD, et al. Novel carbapenem-hydrolyzing $\beta$ lactamase, KPC-1, from a carbapenem-resistant strain of Klebsiella pneumoniae. Antimicrob Agents Chemother. 2001;45(4):1151-61. https://doi.org/10.1128/AAC.45.4.1151.

12. Miriagou V, Tzouvelekis LS, Rossiter S, Tzelepi E, Angulo FJ, Whichard JM. Imipenem resistance in a Salmonella clinical strain due to plasmid-mediated class A carbapenemase KPC-2. Antimicrob Agents Chemother. 2003;47(4):1297-300. https://doi. org/10.1128/AAC.47.4.1297-1300.2003.

13. Moland ES, Hanson ND, Herrera VL, Black JA, Lockhart TJ, Hossain A, et al. Plasmid-mediated, carbapenem-hydrolysing $\beta$ lactamase, KPC-2, in Klebsiella pneumoniae isolates. J Antimicrob Chemother. 2003;51(3):711-4. https://doi.org/10. 1093/jac/dkg124.

14. Woodford N, Tierno PM, Young K, Tysall L, Palepou MF, Ward E, et al. Outbreak of Klebsiella pneumoniae producing a new carbapenem hydrolyzing class A of beta-lactamase, KPC-3, in a New York medical center. J Antimicrob Agents Chemother. 2004;48(12):4793-9. https://doi.org/10.1128/AAC.48.12.4793.

15. Abdallah M, Olafisoye O, Cortes C, Urban C, Landman D, Ghithan $\mathrm{M}$, et al. Rise and fall of KPC-producing Klebsiella pneumoniae in New York City. J Antimicrob Chemother. 2016;71(10):2945-8. https://doi.org/10.1093/jac/dkw242. This reference depicted that some hospitals in New York City were reporting that nearly half of their $\mathrm{K}$. pneumoniae isolates carried $\boldsymbol{b l a}_{K P C}$ ? genes

16. Park SO, Liu J, Furuya EY, Larson EL. Carbapenem-resistant Klebsiella pneumoniae infection in three New York City hospitals trended downwards from 2006 to 2014. Open Forum Infect Dis. 2016;3(4):ofw222. https://doi.org/10.1093/ofid/ofw222. This paper reported that New York City saw a significant decline in prevalence of Klebsiella pneumoniae carbapenemases and suggested that reduction of indwelling device utilization improved techniques for sterilization of endoscopes, and application of infection prevention strategies may have contributed to this decline

17. Naas T, Nordmann P. Plasmid-mediated carbapenem-hydrolyzing beta-lactamase KPC in a Klebsiella pneumoniae isolate from France. J Antimicrob Agents Chemother. 2005;49(10):4423-4. https://doi.org/10.1128/AAC.49.10.4423.

18. Munoz-Price LS, Poirel L, Bonomo R, Schwaber MJ, Daikos GL, Cormican M, et al. Clinical epidemology of the global expansion of Klebsiella pneumoniae carbapenemases. Lancet Infect Dis. 2013;13(9):785-96. https://doi.org/10.1016/S1473-3099(13) 70190-7.

19.• Campos AC, Albiero J, Ecker AB, Kuroda CM, Meirelles L, Polato A, et al. Outbreak of Klebsiella pneumoniae carbapenemase-producing $\mathrm{K}$ pneumoniae: a systematic review. Am J Infect Control. 2016;44(11):1374-80. https://doi.org/10.1016/j.ajic.2016.03.022.
This article reviewed outbreaks of Klebsiella pneumoniae carbapenemases and factors associated with them

20. Okamoto K, Lin MY, Haverkate M, Lolans K, Moore NM, Weiner $\mathrm{S}$, et al. Modifiable risk factors for the spread of Klebsiella pneumoniae carbapenemase-producing Enterobacteriaceae among long-term acute-care hospital patients. Infect Control Hosp Epidemiol. 2017;38(6):670-7. https://doi.org/10.1017/ice.2017. 62. This article reviewed the risk factors for acquisition of Klebsiella pneumoniae carbapenemase-producing organisms

21. Van Duin D, Perez F, Rudin SD, Cober E, Hanrahan J, Ziegler J, et al. Surveillance of carbapenem-resistant Klebsiella pneumoniae: tracking molecular epidemiology and outcomes through a regional network. Antimicrob Agents Chemother. 2014;58(7):4035-41. https://doi.org/10.1128/AAC.02636-14.

22. Prabaker K, Lin MY, McNally M, Cherabuddi K, Ahmed S, Norris A, et al. Transfer from high-acuity long-term care facilities is associated with carriage of Klebsiella pneumoniae carbapenemase-producing Enterobacteriaceae: a multihospital tudy. Infect Control Hosp Epidemiol. 2012;33(12):1193-9. https://doi.org/10.1086/ 668435.

23. Lübbert C, Lippmann N, Busch T, Kaisers UX, Ducomble T, Eckmanns T, et al. Long-term carriage of Klebsiella pneumoniae carbapenemase-2-producing $\mathrm{K}$ pneumoniae after a large singlecenter outbreak in Germany. Am J Infect Control. 2014;42(4): 376-80. https://doi.org/10.1016/j.ajic.2013.12.001.

24. Leitner E, Zarfel G, Luxner J, Herzog K, Pekard-Amenitsch S, Martin H, et al. Contaminated handwashing sinks as the source of a clonal outbreak of KPC-2-producing Klebsiella oxytoca on a hematology ward. Antimicrob Agents Chemother. 2015;59(1): 714-6. https://doi.org/10.1128/AAC.04306-14. This paper described a prolonged outbreak involving $K$. oxytoca with $b_{K P C}$ ? in an Austrian hematology ward for which contaminated mesh sink drains may have been the source. Renewed enforcement of contact precautions, hand hygiene, and cleaning of the environment eventually controlled the outbreak

25. Munoz-Price LS, Hayden MK, Lolans K, Won S, Calvert K, Lin M, et al. Successful control of an outbreak of Klebsiella pneumoniae carbapenemase - producing K. pneumoniae at a long-term acute care hospital. Infect Control Hosp Epidemiol. 2010;31(4):341-7. https://doi.org/10.1086/651097.

26. Hayden MK, Lin MY, Lolans K, Weiner S, Blom D, Moore NM, et al. Prevention of colonization and infection by Klebsiella pneumoniae carbapenemase-producing enterobacteriaceae in long-term acute-care hospitals. Clin Infect Dis. 2015;60(8):1154 61. https://doi.org/10.1093/cid/ciu1173. This paper investigated interventions to reduce patient to patient transmission of Klebsiella pneumoniae carbapenemases

27.• Crum-Cianflone NF, Sullivan E, Ballon-Landa G. Fecal microbiota transplantation and successful resolution of multidrug-resistantorganism colonization. J Clin Microbiol. 2015;53(6):1986-9. https://doi.org/10.1128/JCM.00820-15. This paper discussed a novel approach of displacing multi-drug resistant organisms by using fecal microbiota transplantation

28. Gallagher JC, Kuriakose S, Haynes K, Axelrod P. Case-casecontrol study of patients with carbapenem-resistant and thirdgeneration-cephalosporin-resistant Klebsiella pneumoniae bloodstream infections. Antimicrob Agents Chemother. 2014;58(10): 5732-5. https://doi.org/10.1128/AAC.03564-14.

29. Papadimitriou-Olivgeris M, Marangos M, Christofidou M, Fligou F, Bartzavali C, Panteli ES, et al. Risk factors for infection and predictors of mortality among patients with KPC-producing Klebsiella pneumoniae bloodstream infections in the intensive care unit. Scand J Infect Dis. 2014;46(9):642-8. https://doi.org/10.3109/ 00365548.2014 .923106$. 
30. Girometti N, Lewis RE, Giannella M, Ambretti S, Bartoletti M, Tedeschi S, et al. Klebsiella pneumoniae bloodstream infection. Medicine. 2014;93(17):298-309. https://doi.org/10.1097/MD. 0000000000000111.

31. Gutiérrez-Gutiérrez B, Salamanca E, de Cueto M, Hsueh P, Viale P, Pano-Pardo JR, et al. Effect of appropriate combination therapy on mortality of patients with bloodstream infections due to carbapenemase-producing Enterobacteriaceae (INCREMENT): a retrospective cohort study. Lancet Infect Dis. 2017;17(7):726-34. https://doi.org/10.1016/S1473-3099(17)30228-1.

32. Adler A, Ben-Dalak M, Chmelnitsky I, Carmeli Y. Effect of resistance mechanisms on the inoculum effect of carbapenem in Klebsiella pneumoniae isolates with borderline carbapenem resistance. Antimicrob Agents Chemother. 2015;59(8):5014-7. https:// doi.org/10.1128/AAC.00533-15.

33. Tumbarello M, Trecarichi EM, De Rosa FG, Giannella M, Giacobbe DR, Bassetti M, et al. Infections caused by KPCproducing Klebsiella pneumoniae: differences in therapy and mortality in a multicentre study. J Antimicrob Chemother. 2015;70(7): 2133-43. https://doi.org/10.1093/jac/dkv086.

34. Bulik CC, Nicolau DP. Double-carbapenem therapy for carbapenemase-producing Klebsiella pneumoniae. Antimicrob Agents Chemother. 2011;55(6):3002-4. https://doi.org/10.1128/ AAC.01420-10.

35. Cprek JB, Gallagher JC. Ertapenem-containing double-carbapenem therapy for treatment of infections caused by carbapenem-resistant Klebsiella pneumoniae. Antimicrob Agents Chemother. 2015;60(1):669-73. https://doi.org/10.1128/AAC.01569-15. This article described outcomes of patients that received doublecarbapenem regimens for Klebsiella pneumoniae carbapenemase-producing infections

36. Oliva A, D'Abramo A, D'Agostino C, Ianetta M, Mascellino MT, Gallinelli C, et al. Synergistic activity and effectiveness of a doublecarbapenem regimen in pandrug-resistant Klebsiella pneumoniae bloodstream infections. J Antimicrob Chemother. 2014;69(6): 1718-20. https://doi.org/10.1093/jac/dku027.

37.• De Pascale G, Martucci G, Montini L, Panarello G, Cutuli SL, Di Carlo D, et al. Double carbapenem as a rescue strategy for the treatment of severe carbapenemase-producing Klebsiella pneumoniae infections: a two-center, matched case-control study. Crit Care. 2017;21(1):173. https://doi.org/10.1186/s13054-017$1769-z$. This study evaluated the effiacy of doublecarbapenem coverage reigmens and outcomes compared to standard regimens

38.• Jayol A, Nordmann P, Brink A, Poirel L. Heteroresistance to colistin in Klebsiella pneumoniae associated with alterations in the PhoPQ regulatory system. Antimicrob Agents Chemother. 2015;59(5):2780-4. https://doi.org/10.1128/AAC.05055-14. This paper reviewed mechanisms of resistance of Klebsiella pneumoniae carbapenemases to carbapenems

39. Falagas ME, Rafailidis PI, Matthaiou DK. Resistance to polymyxins: mechanisms, frequency and treatment options. Drug Resist Updat. 2010;13:132-8. https://doi.org/10.1016/j.drup.2010. 05.002 .

40. Bradford PA, Kazmierczak KM, Biedenbach DJ, Wise MG, Hackel M, Sahm DF. Correlation of beta-lactamase production and colistin resistance among Enterobacteriaceae isolates from a global surveillance program. Antimicrob Agents Chemother. 2016;60(3):138592. https://doi.org/10.1128/AAC.01870-15.

41. Bergen PJ, Landersdorfer CB, Zhang J, Zhao M, Le HJ, Nation RL, et al. Pharmacokinetics and pharmacodynamics of "old" polymyxins: what is new? Diagn Microbiol Infect Dis. 2012;74(3): 213-23. https://doi.org/10.1016/j.diagmicrobio.2012.07.010.

42.• et al. Bergen PJ, Bulman ZP, Landersdorfer CB, Smith N, Lenhard $\mathrm{J}$, Bulitta JB, Optimizing polymyxin combinations against resistant Gram-negative bacteria. Infect Dis Ther. 2015;4(4):391-415. https://doi.org/10.1007/s40121-015-0093-7. This article discussed how to optimize polymyxin administration in combination with other agents for infections due to resistant Gram-negatives

43. Lee GC, Burgess DS. Polymyxins and doripenem combination against KPC-producing Klebsiella pneumoniae. J Clin Med Res. 2013;5(2):97-100. https://doi.org/10.4021/jocmr1220w.

44. Garonzik SM, Li J, Thamlikitkul V, Paterson DL, Shoham S, Jacob $\mathrm{J}$, et al. Population pharmacokinetics of colistin methanesulfonate and formed colistin in critically ill patients from a multicenter study provide dosing suggestions for various categories of patients. Antimicrob Agents Chemother. 2011;55(7):3284-94. https://doi. org/10.1128/AAC.01733-10.

45. Sandri AM, Landersdorfer CB, Jacob J, Boniatti MM, Dalarosa MG, Falci DR, et al. Population pharmacokinetics of intravenous polymyxin B in critically ill patients: implications for selection of dosage regimens. Clin Infect Dis. 2013;57(4):524-31. https://doi. org/10.1093/cid/cit334.

46.• Nation RL, Garonzik SM, Thamlikitkul V, Giamarello-Bourboulis EJ, Forrest A, Paterson DL, et al. Dosing guidance for intravenous colistin in critically ill patients. Clin Infect Dis. 2017;64(5):565-71. https://doi.org/10.1093/cid/ciw839. This paper reviewed the relationship between colistin dosing and renal function and outcomes

$47 . \bullet$ Neuner EA, Gallagher JC. Pharmacodynamic and pharmacokinetic considerations in the treatment of critically Ill patients infected with carbapenem-resistant Enterobacteriaceae. Virulence. 2017;8(4): 440-52. https://doi.org/10.1080/21505594.2016.1221021. This article stressed the importance of the uncertainty of polymyxins to achieve adqueate lung concentrations

48. Polymyxin B [package insert]. Breckenridge Pharmaceutical Inc., Boca Raton, FL; 2016.

49.• Rigatto MH, Oliveira MS, Perdigão-Neto LV, Levin AS, Carrilho CM, Tanita MT, et al. Multicenter prospective cohort study of renal failure in patients treated with colistin versus polymyxin B. Antimicrob Agents Chemother. 2016;60(4):2443-9. https://doi. org/10.1128/AAC.02634-15. This article reviewed the increased risk of renal failure associated with colistin compared to polymyxin

50. Phe K, Lee Y, McDaneld PM, Prasad N, Yin T, Figueroa DA, et al. In vitro assessment and multicenter cohort study of comparative nephrotoxicity rates associated with colistimethate versus polymyxin b therapy. Antimicrob Agents Chemother. 2014;58(5):2740-6. https://doi.org/10.1128/AAC.02476-13.

51. Akajagbor DS, Wilson SL, Shere-Wolfe KD, Dakum P, Charurat ME, Gilliam BL. Higher incidence of acute kidney injury with intravenous colistimethate sodium compared with polymyxin $\mathrm{b}$ in critically ill patients at a tertiary care medical center. Clin Infect Dis. 2013;57(9):1300-3. https://doi.org/10.1093/cid/cit453.

52. Tuon FF, Rocha JL, Formighieri MS, Sfair S, Bertoldi MB, Palmeiro JK, et al. Fosfomycin susceptibility of isolates with blaKPC-2 from Brazil. J Inf Secur. 2013;67(3):247-9. https://doi. org/10.1016/j.jinf.2013.04.017.

53. Ellington MJ, Livermore DM, Pitt TL, Hall LMC, Woodford N. Mutators among CTX-M beta-lactamase-producing Escherichia coli and risk for the emergence of fosfomycin resistance. $\mathrm{J}$ Antimicrob Chemother. 2006;58(4):848-52. https://doi.org/10. 1093/jac/dkl315.

54. Yu W, Shen P, Bao Z, Zhou K, Zheng B, Ji J, et al. In vitro antibacterial activity of fosfomycin combined with other antimicrobials against KPC-producing Klebsiella pneumoniae. Int J Antimicrob Agents. 2017;50(2):237-41. https://doi.org/10.1016/j.ijantimicag. 2017.03.011.

55. Zavascki AP, Klee BO, Bulitta JB. Aminoglycosides against carbapenem-resistant Enterobacteriaceae in the critically ill: the pitfalls of aminoglycoside susceptibility. Expert Rev Anti Infect 
Ther. 2017;15(6):519-26. https://doi.org/10.1080/14787210.2017. 1316193. This article discussed the limitations of aminoglycoside susceptibility and minimum inhibitory concentration datas in serving as valid predictors of clinical success

56. Endimiani A, Hujer KM, Hujer AM, Armstrong ES, Choudhary Y, Aggen JB, et al. ACHN-490, a neoglycoside with potent in vitro activity against multi-drug resistant Klebsiella pnemoniae isolates. Antimicro Agents Chemo Ther. 2009;53:4504-7. https://doi.org/ 10.1128/AAC.00641-09.

57. Kitchel B, Sundin DR, Patel JB. Regional dissemination of KPCproducing Klebsiella pneumoniae. Antimicrob Agents Chemother. 2009;53(10):4511-3. https://doi.org/10.1128/AAC.00784-09.

58. United States Committee on Antimicrobial Susceptibility Testing ( USCAST ). MIC Breakpoint Tables Comparing the Interpretive Criteria of CLSI, EUCAST, USA-FDA and USCAST. 2015:1-8.

59. Tzouvelekis LS, Markogiannakis A, Piperaki E, Souli M, Daikos GL. Treating infections caused by carbapenemase-producing Enterobactericeae. Clin Microbiol Infect Dis. 2014;20:862-72. https://doi.org/10.1111/1469-0691.12697.

60. Alexander BT, Marschall J, Tibbetts RJ, Neuner EA, Dunne WM, Ritchie DJ. Treatment and clinical outcomes of urinary tract infections caused by KPC-producing Enterobacteriaceae in a retrospective cohort. Clin Ther. 2012;34(6):1314-23. https://doi.org/10. 1016/j.clinthera.2012.05.002.

61. Satlin MJ, Kubin CJ, Blumenthal JS, Cohen AB, Furuya E, Wilson $\mathrm{SJ}$, et al. Comparative effectiveness of aminoglycosides, polymyxin $\mathrm{B}$, and tigecycline for clearance of carbapenem-resistant Klebsiella pneumoniae from urine. Antimicrob Agents Chemother. 2011;55(12):5893-9. https://doi.org/10.1128/AAC.00387-11.

62. Tzouvelekis LS, Markogiannakis A, Piperaki E, Souli M, Daikos GL. Treating infections caused by carbapenemase-producing Enterobacteriaceae. Clin Microbiol Infect. 2014;20(9):862-72. https://doi.org/10.1111/1469-0691.12697.

63. Le J, Ashley ED, Neuhauser MM, Brown J, Gentry C, Klepser ME, et al. Consensus aummary of aerosolized antimicrobial agents : application of guideline criteria insights from the Society of Infectious Diseases Pharmacists. Pharmacotherapy. 2010;30(6): 562-84. https://doi.org/10.1592/phco.30.6.562.

64. Sader HS, Castanheira M, Flamm RK, Mendes RE, Farrell DJ, Jones RN. Tigecycline activity tested against carbapenemresistant Enterobacteriaceae from 18 European nations : results from the SENTRY surveillance program ( 2010-2013 ). Diagn Microbiol Infect Dis 2015:83(2):183-186. doi:https://doi.org/10. 1016/j.diagmicrobio.2015.06.011.

65. Van Duin D, Kaye KS, Neuner EA, Bonomo RA. Carbapenemresistant Enterobacteriaceae: a review of treatment and outcomes. Diagn Microbiol Infect Dis. 2013;75(2):115-20. https://doi.org/10. 1016/j.diagmicrobio.2012.11.009.

66. Freire AT, Melnyk V, Kim MJ, Datsenko O, Dzyublik O, Glumcher $\mathrm{F}$, et al. Comparison of tigecycline with imipenem/cilastatin for the treatment of hospital-acquired pneumonia. Diagn Microbiol Infect Dis. 2010;68(2):140-51. https://doi.org/10.1016/j.diagmicrobio. 2010.05.012.

67. Kuti JL, Dandekar PK, Nightingale CH, Nicolau DP. Use of Monte Carlo simulation to design an optimized pharmacodynamic dosing strategy for meropenem. J Clin Pharmacol. 2003;43(10):1116-23. https://doi.org/10.1177/0091270003257225.

68. Di Carlo P, Gulotta G, Casuccio A, Pantuso G, Raineri M, Farulla CA, et al. KPC - 3 Klebsiella pneumoniae ST258 clone infection in postoperative abdominal surgery patients in an intensive care setting : analysis of a case series of 30 patients. BMC Anesthesio. 2013:1-8. https://doi.org/10.1186/1471-2253-13-13.

69. Sbrana F, Malacarne P, Viaggi B, Costanzo S, Lenonetti P, Leonildi $\mathrm{A}$, et al. Carbapenem-sparing antibiotic regimens for infections caused by Klebsiella pneumoniae Carbapenemase - Producing K.
Pneumoniae in intensive care unit. Clin Infect Dis. 2013;56:697700. https://doi.org/10.1093/cid/cis969.

70. FDA. A drug safety communication: FDA warns of increased risk of death with IV antibacterial Tygacil (tigecycline) and approves new Boxed Warning. 2013. http://www.fda.gov/\%5CnDrugs/ DrugSafety/ucm369580.htm.

71. Ehmann DE, Jahić H, Ross PL, Gu RF, Hu J, Kern G, et al Avibactam is a covalent, reversible, non- $\beta$-lactam $\beta$-lactamase inhibitor. Proc Natl Acad Sci. 2012;109(29):11663-8. https://doi.org/ 10.1073/pnas.1205073109.

72. Castanheira M, Williams G, Jones RN, Sader HS. Activity of ceftaroline-avibactam tested against contemporary Enterobacteriaceae isolates carrying $\beta$-lactamases prevalent in the United States. Microb Drug Resist 2014: 0(0):1-5. Doi:https://doi. org/10.1089/mdr.2013.0181.

73. Carmeli Y, Armstrong J, Laud PJ, Newell P, Stone G, Wardman A, et al. Ceftazidime-avibactam or best available therapy in patients with ceftazidime-resistant Enterobacteriaceae and Pseudomonas aeruginosa complicated urinary tract infections or complicated intra-abdominal infections (REPRISE): a randomised, pathogen-directed, phase 3 study. Lancet Infect Dis. 2016;16(6):661-73. https://doi.org/10.1016/S1473-3099(16)30004-4. This study illustrated the efficacy of ceftazidime-avibactam in patients infected with resistant organisms

74. Endimiani A, Hujer KM, Hujer AM, Pulse ME, Weiss WJ, Bonomo RA. Evaluation of ceftazidime and NXL104 in two murine models of infection due to KPC-producing Klebsiella pneumoniae. Antimicrob Agents Chemother. 2011;55:82-5. https://doi.org/10.1128/AAC.01198-10.

75. Macvane SH, Crandon JL, Nichols WW, Nicolau DP. In vivo efficacy of humanized exposures of ceftazidime-avibactam in comparison with ceftazidime against contemporary Enterobacteriaceae isolates. Antimicrob Agents Chemother. 2014;58:6913-9. https://doi. org/10.1128/AAC.01198-10.

76. Gugliandolo A, Caio C, Mezzatesta ML, Rifici C, Bramanti P, Stefani S, et al. Successful ceftazidime-avibactam treatment of MDR-KPC-positive Klebsiella pneumoniae infection in a patient with traumatic brain injury. Medicine (Baltimore). 2017;96(31): e7664. https://doi.org/10.1097/MD.0000000000007664.

77.• Wu G, Abraham T, Lee S. Ceftazidime-Avibactam for treatment of carbapenem-eesistant Enterobacteriaceae bacteremia. Clin Infect Dis. 2016;63(8):1147-8. https://doi.org/10.1093/cid/ciw491. This article evaluated the efficacy of the new-beta lactam inhibitor combination for the treatment of carbapenem resistant Enterobacteriacea bacteremia

78. Jacobs DM, DiTursi S, Ruh C, Sharma R, Claus J, Banjade R, et al. Combination treatment with extended-infusion ceftazidime/ avibactam for a KPC-3-producing Klebsiella pneumoniae bacteraemia in a kidney and pancreas transplant patient. Int $\mathrm{J}$ Antimicrob Agents. 2016;48(2):225-7. https://doi.org/10.1016/j. ijantimicag.2016.06.002.

79. King M, Heil E, Kuriakose S, Bias T, Huang V, El-Beyrouty C, et al. Multicenter study of outcomes with ceftazidime-avibactam in patients with carbapenem-resistant Enterobacteriaceae infections. Antimicrob Agents Chemother. 2017;61(7):e00449-17. https:// doi.org/10.1128/AAC.00449-17.

80.• Shields RK, Nguyen MH, Chen L, Press EC, Potoski BA, Marini RA, et al. Ceftazidime-avibactam is superior to other treatment regimens against carbapenem-resistant Klebsiella pneumoniae bacteremia. Antimicrob Agents Chemother. 2017;61(8) https://doi.org/ 10.1128/AAC.00883-17. This article showed superiority of ceftazidime-avibactam over available options for the treatment of carbapenem-reisistant bacteremia

81.• Van Duin D, Lok JJ, Earley M, Cober E, Richter S, Perez F, et al. Colistin vs. ceftazidime-avibactam in the treatment of infections due to carbapenem-resistant Enterobacteriaceae. Clin Infect Dis. 
2017; cix 783 https://doi.org/10.1093/cid/cix783/4103289. This study showed that ceftazidime-avibactam is better than colistin for treatment of carbapenem-resistant Enterobacteriaceae

82.• Humphries RM, Yang S, Hemarajata P, Ward KW, Hindler JA, Miller SA, et al. First report of ceftazidime-avibactam resistance in a KPC-3-expressing Klebsiella pneumoniae isolate. Antimicrob Agents Chemother. 2015;59(10):6605-7. Doi:https://doi.org/10. 1128/AAC.01165-15. This was the the first report of ceftazidime-avibactam resistance in a KPC isolate, indicating that KPCs are evolving

83. Shields RK, Nguyen MH, Press EG, Chen L, Kreiswirth BN, Clancy CJ. Emergence of ceftazidime-avibactam resistance and restoration of carbapenem susceptibility in Klebsiella pneumoniae carbapenemase-producing $\mathrm{K}$ pneumoniae: a case report and review of literature. Open Forum Infect Dis. 2017;4(3):22-5. https://doi. org/10.1093/ofid/ofx101.

84. Lapuebla A, Abdallah M, Olafisoye O, Cortes C, Urban C, Quale J, et al. Activity of meropenem combined with RPX7009, a novel beta-lactamase inhibitor, against Gram-negative clinical isolates in New York City. Antimicrob Agents Chemother. 2015;59(8):485660. https://doi.org/10.1128/AAC.00843-15. This study illustrated the efficacy of the novel beta-lactamse inhibitor, RPX7009, against KPCs

85. Kaye K, Vazquez J, Mathers, A, Daikos G, Alexander E, Loutit J, et al. Clinical outcomes of serious infections due to carbapenemresistant Enterobacteriaceae (CRE) in TANGO-II (a phase 3 study of the treatment of CRE infections). Poster Presentation at IDWeek San Diego, CA; 2017. This presentation provided the outcome data of patients treated with meropenem-vaborbactam for treatment of CRE infections.

86. Kohira N, West J, Ito A, Ito-Horiyama T, Nakamura R, Sato T, et al. In vitro antimicrobial activity of a siderophore cephalosporin, S-649266, against Enterobacteriaceae clinical isolates, including carbapenem-resistant strains. Antimicrob Agents Chemother. 2016;60(2):729-34. https://doi.org/10.1128/AAC.01695-15.
87. Achaogen. (2016). Achaogen announces positive results in phase 3 cUTI and CRE clinical trials of plazomicin. Retrieved from http:// investors.achaogen. com/releasedetail.cfm?ReleaseID=1003671.

88. Lapuebla A, Abdallah M, Olafisoye O, Cortes C, Urban C, Landman $\mathrm{J}$, et al. Activity of imipenem with relebactam against gram-negative pathogens from New York City. Antimicrob Agents Chemother. 2015;59(8):5029-31. https://doi.org/10.1128/ AAC.00830-15. This study evaluated the activity of imipenem with relebactam against Klebsiella pneumoniae carbapenemases

89. Livermore DM, Warner M, Mushtaq S. Activity of MK-7655 combined with imipenem against enterobacteriaceae and Pseudomonas aeruginosa. J Antimicrob Chemother. 2013;68(10):2286-90. https://doi.org/10.1093/jac/dkt178.

90. Zhanel GG, Cheung D, Adam H, Zelentisky S, Golden A, Schweizer F, et al. Review of eravacycline, a novel fluorocycline antibacterial agent. Drugs. 2016;76(5):567-88. https://doi.org/10. 1007/s40265-016-0545-8.

91. Sutcliffe JA, O'Brien W, Fyfe C, Grossman TH. Antibacterial activity of eravacycline (TP-434), a novel fluorocycline, against hospital and community pathogens. Antimicrob Agents Chemother. 2013;57(11):5548-58. https://doi.org/10.1128/AAC.01288-13.

92. Abdallah M, Olafisoye O, Cortes C, Urban C, Landman D, Quale J. Activity of eravacycline against Enterobacteriaceae and Acinetobacter baumannii, including multidrug-resistant isolates, from New York City. Antimicrob Agents Chemother. 2015;59(3): 1802-5. https://doi.org/10.1128/AAC.04809-14. This study illustrated the activity of eravacycline against Klebsiella pneumoniae carbapenemase-producing organisms

93.• Solomkin J, Evans D, Slepavicius A, Lee P, Marsh A, Tsai L, et al. Assessing the efficacy and safety of eravacycline vs ertapenem in complicated intra-abdominal infections in the investigating Gramnegative infections treated with Eravacycline (IGNITE 1) trial. JAMA Surg. 2017;152(3):224. https://doi.org/10.1001/jamasurg. 2016.4237. This study showed the effiicacy of eravacycline for treatment of complicated intra-abdominal infections 